\title{
Teachers' working time as a risk factor for their mental health - findings from a cross- sectional study at German upper-level secondary schools
}

\author{
Steffi Kreuzfeld ${ }^{*} \mathbb{0}$, Christoph Felsing and Reingard Seibt[1]
}

\begin{abstract}
Background: The work of teachers has changed due to an increase in the range of tasks. However, there is a lack of current information on working hours, task distribution and the possible health effects.

Methods: For the first time for Germany as a whole, a cross-sectional survey determined how long teachers at upperlevel secondary schools work per week, what influences their working hours and how different recording methods affect the total working hours. To this end, 6,109 full-time teachers estimated their working hours based on twelve categories and then documented these daily over 4 weeks. Afterwards, the effects of long working hours on teachers' ability to recover and emotional exhaustion were analysed.

Results: The article shows the large interindividual variance in the working hours of teachers and a significant influence of sex, age, and subject profile. Self-reported working hours varied substantially by method used to record working time with work time reported via daily diaries totaling $2 \mathrm{~h}$ per week more than hours recorded by a single estimation.

A substantial proportion of the teachers (36\%) work longer per week than European guidelines allow (> $48 \mathrm{~h}$ ); $15 \%$ work even more than $55 \mathrm{~h}$ per week. Teachers who work more than $45 \mathrm{~h}$ per week suffer more often from inability to recover (46\%) and emotional exhaustion (32\%) than teachers who work less than $40 \mathrm{~h}$ per week (26\% and $22 \%$ respectively).
\end{abstract}

Conclusions: Taking professional experience and teaching subjects into account could in future contribute to a fairer distribution of workload among teachers. This could protect individual teachers from long working hours, ensure sufficient recovery and also reduce the risk of emotional exhaustion. In order to identify teachers whose health is at risk at an early stage, voluntary preventive care offers would be considerably helpful.

Keywords: Full-time teachers, Long working hours, Workload, Methods of time recording, Upper-level secondary education, Inability to recover, Emotional exhaustion

*Correspondence: steffi.kreuzfeld@uni-rostock.de

Institute for Preventive Medicine of the Rostock University Medical Center, St.-Georg-Str. 108, D-18055 Rostock, Germany

\section{Background}

Researchers from different countries have long reported high workloads and time pressure as among the main factors associated with stress in the teaching profession [1-4]. Due to the complexity of the professional requirements, however, it is important to describe the workload 
more precisely in the form of suitable indicators, e.g. by the number of hours teachers need for a wide variety of tasks [5]. For decades, studies in Germany have provided indications that at least some teachers work excessively long weekly hours [6]. In a comparison of different types of schools (primary, lower-level secondary, upper-level secondary), it is noticeable that upper-level secondary school teachers work the longest of all teachers $[7,8]$. However, there are no current statements on the total working hours and task structure of teachers at upper-level secondary schools across Germany. The only nationwide survey on working hours, which also included upper-level secondary school teachers and is considered representative took place in 1973 exclusively in the western part of Germany [9].

Long working hours can have a negative impact on well-being $[10,11]$ as well as physical and mental health [12-16]. Evidence suggests that risk of work-related stress and burnout increase with the number of working hours per week [17]. Nevertheless, it can be difficult for teachers to limit their working hours. Their own demands for good quality teaching and the expectations of pupils, parents, colleagues and the public force some of them to overcommit themselves, even though they realise that they are putting their health at risk. Many teachers work in the evenings and at weekends [18]. This not only reduces the time needed for recreation but also the possibility of detaching from work. However, this detachment from work is an essential prerequisite for recovery processes [19]. If teachers do not succeed in distancing themselves from the content of work, physiological activation which lasts longer than work can hinder recovery processes. As a result, the consequences of previous activities cannot be fully compensated for, so that the teacher's own performance reserves are chronically overtaxed [20]. In this respect, both long working hours and shortened regeneration times are significant for health $[21,22]$, especially with regard to exhaustion.

To reduce work-related stress and the risk of exhaustion, it is therefore necessary to record teachers' working hours and range of tasks as precisely as possible and to recognise highly stressed colleagues at an early stage.

There is consensus that the working hours of teachers depend both on the working conditions (e.g. type of school, subjects taught) and on their individual skills and attitudes [7, 23-25]. However, data on the influence of sex and age on working hours are inconsistent $[6,26]$. The factors mentioned have an effect in particular on the amount of time required for the preparation and followup of lessons as well as corrections.

In Germany and most European countries, the working hours of teachers are largely regulated by the number of mandatory teaching hours per week. Regulations in some countries specify attendance times at school as well as total weekly or annual working hours. Only in parts of Belgium and Liechtenstein is teachers' working time exclusively defined by teaching hours; in the Netherlands and Denmark only the total annual working time is regulated by law $[27,28]$.

Nevertheless, in comparison to other occupational groups, it is difficult to determine the exact working hours of teachers, since teaching itself only makes up less than half of the total working time. The other part of the working time includes extra-curricular activities, some of which have to be performed at school (e.g. conferences, further training), but mostly at home (e.g. preparation and follow-up of lessons, correcting and grading student work). This proportion of working hours is to be organised independently and configured accordingly. In addition, working hours are subject to strong fluctuations over the week and year.

The proportion of time spent teaching averages $43 \%$ of total working time in OECD countries, but varies between 32\% (Poland, Turkey) and 63\% in Scotland [7]. Due to the increase in extra-curricular tasks, it has been observed that the proportion of time for actual teaching has decreased in the more recent studies $[25,29,30]$.

In Germany, there have been repeated studies on the working hours of teachers in various types of school since the 1960s (overview: [6]). Since the findings from these were primarily written in German, they have hardly entered international literature. Two main methods of recording working hours have been used in Germany: on the one hand, the estimation of an average school week $[23,24,31]$, and on the other hand, daily documentation based on pre-determined activity categories over a specified period of time [32-34].

The advantage of the estimation method over the diary method is that it is much less time-consuming. The total weekly working time is determined in the context of interviews or questionnaires either generally or differentiated, based on teacher-specific activity categories. A major disadvantage of the estimation method, however, is that current influences on working time (e.g. increased correction times) or sick days are not often considered.

Documentation of daily working time has been carried out using standardised protocols with defined activity categories, either as a paper version [9] as an electronic version [33] or as a browser-based recording system [3234]. The number of specified job categories has ranged between two and 205 activities in the various studies.

For the acceptance and appropriateness of the working time protocols, it is crucial that the activity categories are understandable and unambiguous and that they reflect the entire spectrum of methodological-didactic, pedagogical, and administrative activities of individual 
teachers. At the same time, their number must be limited so that the documentation of the working hours remains clear and can be carried out within an acceptable amount of time. The definition of the activity categories therefore always represents a compromise between accuracy and the practicability of time recording.

Large, international studies by the OECD on the working time of teachers have used similar methods and found that the average documented working time tends to be higher when it is not only estimated with a single question, but also recorded in a more differentiated manner based on specified activities [35].

\section{Aim of the study}

As part of a nationwide study at upper-level secondary schools in Germany the research therefore investigated how long full-time teachers currently work per week and which factors influence their working hours. For this purpose, two different recording methods (estimation and diary) were used and compared in terms of determining the total working time. Subsequently, this study examined whether longer weekly working hours are associated with teachers' inability to recover or emotional exhaustion.

\section{Methods}

\section{Recruitment of study participants}

The cross-sectional study on the working hours of upperlevel secondary school teachers (hereinafter: teachers) took place between January and April 2018 in all sixteen German federal states. In each federal state, a 4-week study period with average workload (no extraordinary activities due to exams, extensive corrections, class trips, etc.) was selected to ensure comparable conditions for working time recording nationwide. In the run-up to the study, posters and flyers were used to promote voluntary participation at all upper-level secondary schools. Immediately before the start of the study, all teachers in the school received an information letter on the study with information on data protection, implementation, and data evaluation as well as the conditions of participation and access to the study. Anonymity of data was ensured via transaction numbers (TANs) and an eightdigit personal code. This code was created according to predefined specifications and was only known to the participant. The data were collected via an online portal at the university.

The following groups of persons were excluded from participation: teachers on paternal leave, trainee teachers, teachers with long-term illnesses, teachers at vocational schools as well as temporary staff.

\section{Execution and data acquisition}

Working time and activity distribution were determined in parallel using an online questionnaire (OQ) and an online working time protocol (in short: online protocol - OP). Both tools were developed by the authors for this study and used the same activity categories (see Additional files 1 and 2). In the operationalisation of the teacher-specific range of activities, the diverse tasks were transferred into practicable, suitably clear categories of activity. The determination of the categories was based on previous studies on teachers' working hours [36]. The activity categories were restricted to twelve to develop a suitable variant for electronic recording on a mobile device.

First of all, the teachers used the OQ to estimate their working time for 1 week of average workload based on the defined activity categories (Table 1). At the same time, the OQ was used to document socio-demographic, job-specific as well as health-related data from the participants.

The teachers then documented their working hours each day over a period of 4 weeks (28 days) using the activity categories in the OP. In addition, this included whether the teacher had been present at the school and had taught on each day of class. In the case of absence, the appropriate reason had to be selected (own illness / illness of relatives / regular class-free day / other personal or professional reasons). In the case of sick days, the teachers also indicated whether and to what extent schoolwork was carried out.

In order to simplify the documentation of working hours in everyday school life and to avoid distortion due to lapse of memory, the activities could first be recorded on paper (table of categories) and later transferred to the $\mathrm{OP}$ at any time.

\section{Mental health measurements}

The health-related characteristics considered were inability to recover and emotional exhaustion.

The inability to recover (IR) is a subscale of the questionnaire for the analysis of stress-relevant coping requirements (German: FABA) [37] which describes the inability to cope with work-related stress to the detriment of one's own recovery. IR is measured using six items on a four-point Likert scale $(1=$ does not apply at all to 4 $=$ strongly applies). By summing the values (range: 6-24 points), interpretation into normal, noticeable and very noticeable is given [37]. The reliability of the subscale is rated as good, Cronbach's alpha is given as 0.79 [38]. In the present study, a Cronbach's alpha of 0.80 was determined for IR, which was considered acceptable and was at the limit of the good range [39]. 
Table 1 Categories of teacher-specific activities

\begin{tabular}{|c|c|}
\hline Category & Description \\
\hline \multicolumn{2}{|l|}{ Teaching } \\
\hline Lessons & Number of lessons \\
\hline Substitute lessons & Number of lessons substituting for colleagues \\
\hline \multicolumn{2}{|l|}{ Teaching-related activities } \\
\hline Preparation / follow-up & Preparation (e.g. class tests, exams) and follow-up time of lessons \\
\hline Corrections / marks & Correction and grading of pupils' work (e.g. exams, homework) \\
\hline Projects / excursions & Implementation of projects, excursions, class trips, pupil exchanges \\
\hline \multicolumn{2}{|l|}{ Non-teaching activities } \\
\hline Pupils / parents & $\begin{array}{l}\text { Extracurricular work with pupils (e.g. pupil counselling, conversations regarding pupil education, communication) } \\
\text { and co-operation with parents }\end{array}$ \\
\hline Administration & Administrative tasks and organisational matters (e.g. certifications, planning of events, school trips or projects, orders) \\
\hline Colleagues / teamwork & Teamwork and dialogue with colleagues, co-operation with colleagues \\
\hline Inclusion & Tasks within the scope of pupils' inclusion \\
\hline Integration & Tasks within the scope of pupils' integration \\
\hline Supervision & Supervision times during breaks \\
\hline All other tasks & All-day school activities, evaluations, safety, trainings, mentoring, commission memberships, staff council activities \\
\hline
\end{tabular}

Emotional Exhaustion (EE) was measured with the German translation of the Maslach Burnout InventoryGeneral Survey (MBI-GS) [40]. EE is one of three subscales of the MBI and is considered by many researchers to be the core component of burnout. It measures the frequency of occurrence of symptoms using five items on a seven-point Likert scale $(0=$ never up to $6=$ daily). The mean value allows the classification into low, normal or high emotional exhaustion. The validity of the MBI-GS was proven by Schaufeli et al. [40]: Cronbach's alpha was 0.87 for EE. For the burnout subscale EE of the study presented here, Cronbach's alpha was 0.85 , and thus, according to Blanz [39], it was in the range of good.

\section{Quality management of data collection}

In October 2017, both recording methods were evaluated by eight teachers. The activity categories were then tested for comprehensibility, uniqueness, and freedom from errors in a preliminary study at four upper-level secondary schools in different federal states. A list of answers to frequently asked questions (FAQ) was then made available on the study website. In addition, there was the possibility of telephone and electronic queries to the team of investigators over the entire investigation period.

In both the OQ and in the OP, input aids and default settings prevented implausible time entries. Only study participants for whom both an OQ and an OP were available were included in the data analysis. Using the personal code, both documents could be merged for data evaluation. The completeness of the information in the OP was then checked. Participants who recorded their working hours on fewer than 21 out of 28 days were not included in the data analysis.

\section{Sample}

A total of more than 20,000 upper-level secondary school teachers took part in the study. Of these, 18,791 filled out the complete OQ, so that complete data sets were available for all variables of these participants. This represents $11 \%$ of all secondary school teachers in Germany. In terms of sex and age, this sample was comparable with the total of all German upper-level secondary school teachers. Only the group of teachers over 60 was underrepresented (5\% instead of $12 \%$ ), and in terms of employment, part-time teachers had participated slightly more often than their share of all upper-level secondary school teachers (46\% instead of $38 \%$ ).

The OQ and OP codes matched and the quality requirements in the OP were satisfied by 14,338 participants. About $84 \%$ of these records $(n=12,014)$ were related to teachers who primarily give lessons. In contrast, $16 \%$ of the records referred to teachers who were employed as headmasters or deputy headmasters or who performed other administrative tasks and functions within the school to a considerable extent and therefore gave significantly fewer lessons. For comparison of the two recording methods reported here, a sample should be studied that was as homogeneous as possible. Therefore, only datasets from full-time teachers with a reduction of up to three hours (reduced teaching hours) were analysed $(n=6,109)$. The composition of the sample is shown in Table 2: women (56\%) are slightly more often represented than men (44\%). 
Table 2 Characteristics of the sample

\begin{tabular}{lll}
\hline Variables & $\begin{array}{l}\text { Number of } \\
\text { teachers }\end{array}$ & $\%$ \\
\hline Full-time teachers & 6109 & 100 \\
Sex & & \\
- male & 2680 & 43.9 \\
- female & 3429 & 56.1 \\
Age groups [years] & & \\
- 20 - 29 & 636 & 10.4 \\
- 30 - 39 & 2442 & 40.0 \\
- 40 - 49 & 1535 & 25.1 \\
- 50 - 59 & 1177 & 19.3 \\
- 60 - 67 & 319 & 5.2 \\
Employment & & \\
- civil servants ${ }^{\mathrm{a}}$ & 5267 & 86.2 \\
- other employees & 842 & 13.8 \\
Subject profile & & \\
- languages & 990 & 16.2 \\
- social sciences & 220 & 3.6 \\
- natural sciences & 1310 & 21.4 \\
- languages and social sciences & 1497 & 24.5 \\
- languages and natural sciences & 373 & 6.1 \\
- social sciences and natural sciences & 471 & 7.7 \\
- art, music, sports & 126 & 2.1 \\
- subject combinations with art, music, sports & 1122 & 18.4 \\
\hline Notes: \%: frequencies in \% & & \\
a In the state education system, many teachers gain the status of civil servants, \\
which affords them certain rights and privileges
\end{tabular}

The average age is $41.3 \pm 10.2$ years and does not differ between the sexes. Half of the participants were between 20 and 39 years old. Science, languages and combinations of languages and social sciences are the most commonly taught subjects.

\section{Data processing}

Prior to the statistical calculations, the entire dataset was checked for implausible information. The number of teaching hours and the reduction in hours (reduced teaching time) was checked in the OQ on the basis of information on age and the special tasks of the teacher. The range of time for the individual activity categories was examined in the OP for statistical outliers every 28 days. Extreme values were replaced by subject-specific mean values within the individual activity categories.

The times in the activity categories in the OQ and in the OP were indicated in minutes - with the exception of the teaching and substitute lessons (45-min units). To determine the total weekly working time, all information was converted into hours. In the OP, the average values over 4 weeks were calculated for all activity categories, provided there were no sick days $(74 \%$ of the full-time data records). If there were any sick days documented, these weeks were not taken into account when calculating the average weekly working time. Instead, the average value was calculated from the remaining weeks without sick days. During the investigation period, $10 \%$ of the participating full-time teachers were sick for one day, another $14 \%$ were sick for two to five days and $2 \%$ were absent from work for six to ten days due to illness.

\section{Statistical analysis}

The statistical analysis of the data recorded was carried out using the programme "Statistical Package for the Social Science" (SPSS, Version 25) for Windows. Differences between the working hours and activity categories of the $\mathrm{OQ}$ and $\mathrm{OP}$ were examined using general linear models with repeated measurements and univariate covariance analyses - controlled for sex, age groups and subject profile. Post-hoc tests (Bonferroni) were carried out for significant $p$-values. The $\mathrm{Chi}^{2}$ test was used to test the differences between categorical variables.

The significant level of all statistics was set at $p<$ 0.05 . Since even small differences produce significant results in large samples, effect sizes were determined. The partial eta squared $\left(\eta^{2}\right.$ partial $)$ was used to express the analysis of variance and Cohen's $d$ for interpretation the $\mathrm{Chi}^{2}$-test. Both effect sizes were interpreted according to the conventions of Cohen [41]. In the analyses of variance and the $\mathrm{Chi}^{2}$ tests, small effect sizes from $\eta_{\text {partial }}^{2}=0.01$ or $\mathrm{d}=0.20$ are considered statistically significant effects.

To highlight the relationship between weekly working hours and the health-related characteristics (inability to recover and emotional exhaustion), teachers were divided into two (extreme) groups: those working less than $40 \mathrm{~h}$ per week ( $n=1,796,29 \%)$ and those working more than $45 \mathrm{~h}$ per week $(n=2,983,49 \%)$. This division is based on the one hand on the labor law requirement for full-time employment ( $40 \mathrm{~h} /$ week) and on the other hand on the fact that full-time teachers in Germany work an average of $45 \mathrm{~h}$ per week [42]. The third group, in which teachers work between $40-45 \mathrm{~h}$ per week $(n=1,330,22 \%)$, was consciously excluded from the analyses.

Differences between the two extreme groups were examined for the characteristics of working hours and health with the help of univariate variance analyses and $\mathrm{Chi}^{2}$ tests, and for correlations between working hours and health-related characteristics with the Pearson product-moment correlation. Correlation coefficients were interpreted according to Bühl [43], where $r \pm \leq 0.10$ is considered independent of each other. 


\section{Results}

Influence of the method and the covariables on weekly working time

The amount of weekly working time (WWT) differs significantly between the two methods of data recording ( $p=0.001$; small effect) (Table 3$)$. With the OQ, the sample examined estimates the average WWT at $42.8 \mathrm{~h}$. However, if the WWT is determined by OP, the WWT is $45.2 \mathrm{~h}$. This results in a significant difference of $2.4 \mathrm{~h}$ compared to estimated working time $(p<0.001)$.

The results for the working time are also influenced by a significant sex and age effect and by the subject profile; these effects occur regardless of the recording method (Tables 3 and 4).

On average, women work significantly longer per week than men ( $p<0.001$; small effect). Regarding the age effect, it should be noted that younger colleagues (20 - 29 years) work the longest (OP: $47.0 \mathrm{~h} /$ week). Older colleagues (60 - 67 years) on the other hand work the least amount of time (OP: $42.2 \mathrm{~h} /$ week). This effect could be demonstrated in both recording methods.

In addition, WWT are significantly influenced by the subject profile ( $p<0.001$; small effect). Teachers who teach one or more languages, regardless of the method, document the longest WWT (OP: 46.5 h/week), followed by the subject profile from languages and natural or social sciences (OP: $>45 \mathrm{~h} /$ week) (Table 4).

For the average WWT (Table 4), high deviations are noticeable up and down in the form of standard deviations. The differences in WWT between teachers are therefore up to $18.6 \mathrm{~h}$ per week. On the basis of the recorded data (OP), $49 \%$ of the teachers $(n=2,983)$ worked more than $45 \mathrm{~h}$ per week during the observation period. About $36 \%$ of the teachers $(n=2,199)$ exceeded the European working time limits of $48 \mathrm{~h}$ weekly, $11 \%(n=672)$ worked more than 55 and $4 \%$ ( $n$ $=244$ ) even more than $60 \mathrm{~h}$ weekly.

\section{Correlation between working time and health-related characteristics}

In order to comprehend what causes the considerable differences in WWT between individual teachers, the volume of teacher-specific activities of the group of teachers who work less than $40 \mathrm{~h}$ per week (29\%) was compared to the group of teachers who work more than $45 \mathrm{~h}$ per week (49\%) (Fig. 1). The difference in mean weekly working hours between the two groups is remarkable and comes to about $16 \mathrm{~h}$, which corresponds to two normal working days. It is evident that it is mainly the extent of teaching-related activities that differs between the working time groups $\left(\eta^{2}\right.$ partial $\geq 0.14$, large effects). This category includes all activities of preparation and the follow-up of lessons and projects as well as correction work.

In the correlation analysis, the categories teaching, teaching-related and non-teaching activities show only very low correlations with each other $(r=0.04$ to -0.15$)$. Accordingly, the amount of time invested in teachingrelated and non-teaching activities does not depend on the number of teaching hours.

Table 5 compares the manifestations of the healthrelated characteristics for the two working time groups. The group of teachers working less than $40 \mathrm{~h}$ per week differs from the group with weekly working hours of more than $45 \mathrm{~h}$ by a significantly increased inability to recover ( $d=0.41$, medium effect $)$ and a significantly higher emotional exhaustion $(\mathrm{d}=0.23$, small effect). When working more than $45 \mathrm{~h}$ per week, almost half of the teachers (46\%) show noticeable recovery values and one third of the teachers (32\%) show high exhaustion values, whereas in the group with a WWT of less than $40 \mathrm{~h}$, this only applies to one quarter ( $26 \%$ and $22 \%$ respectively) of the

Table 3 Main effects of the covariates on the weekly working time (WWT) of full-time teachers $(n=6,109)$

\begin{tabular}{|c|c|c|c|c|c|}
\hline Variables & $\begin{array}{l}\text { WWT Online Questionnaire } \\
M \pm S D \text { [h] }\end{array}$ & $\begin{array}{l}\text { WWT Online Protocol } \\
\mathrm{M} \pm \mathrm{SD}[\mathrm{h}]\end{array}$ & F-value & $p$-value & $\eta_{\text {partial }}^{2}$ \\
\hline & $42.8 \pm 8.1$ & $45.2 \pm 8.7$ & 51.50 & 0.001 & 0.017 \\
\hline \multicolumn{6}{|l|}{ Covariates } \\
\hline Sex & & & 40.39 & $<0.001$ & 0.007 \\
\hline Age group & & & 42.15 & $<0.001$ & 0.007 \\
\hline Subject profile & & & 7.96 & 0.005 & 0.001 \\
\hline \multicolumn{6}{|l|}{ Interaction effects } \\
\hline Method* sex & & & 8.51 & 0.001 & 0.003 \\
\hline Method* age group & & & 3.62 & 0.027 & 0.001 \\
\hline Method ${ }^{*}$ subject profile & & & 4.04 & 0.018 & 0.001 \\
\hline
\end{tabular}

Notes: $M \pm S D$ mean \pm standard deviation. Online Protocol: mean of illness-free weeks. General linear model with measurement repetition; internal subject design: method; design: constant term + sex + age group + subject profile; test variable: $F$-value; $\mathrm{df}=2$; error def $=6,104 ; p$-value: significance (two-sided); $\eta^{2}$ partial partial eta square (effect size): $0.010-0.060=$ small effect, $<0.010=$ none effect [41] 
Table 4 Estimated versus documented weekly working time of full-time teachers $(n=6,109)$

\begin{tabular}{|c|c|c|}
\hline Covariates & $\begin{array}{l}\text { Online Questionnaire } \\
M \pm S D[h]\end{array}$ & $\begin{array}{l}\text { Online Protocol } \\
\mathrm{M} \pm \mathrm{SD}[\mathrm{h}]\end{array}$ \\
\hline \multicolumn{3}{|l|}{ Sex (number of teachers) } \\
\hline - male (2680) & $41.9 \pm 7.8$ & $44.2 \pm 8.6$ \\
\hline - female (3429) & $43.5 \pm 8.2$ & $45.7 \pm 8.7$ \\
\hline F-value & 61.37 & 18.24 \\
\hline$p$-value $\left(\eta_{\text {partial-value }}^{2}\right)$ & $<0.001(0.010)$ & $<0.001(0.012)$ \\
\hline \multicolumn{3}{|l|}{ Age groups [years] (number of teachers) } \\
\hline$-20-29(639)$ & $44.7 \pm 7.9$ & $47.0 \pm 8.8$ \\
\hline$-30-39(2442)$ & $42.9 \pm 8.3$ & $45.2 \pm 8.8]$ \\
\hline$-40-49(1535)$ & $41.9 \pm 7.6$ & $44.6 \pm 8.6$ \\
\hline$-50-59(1177)$ & $43.1 \pm 8.1$ & $44.8 \pm 8.5$ \\
\hline$-60-67(316)$ & $41.0 \pm 8.3$ & $42.2 \pm 8.3$ \\
\hline F-value & 18.75 & 42.06 \\
\hline$p$-value ( $\eta_{\text {partial-value })}^{2}$ & $<0.001(0.012)$ & $<0.001(0.007)$ \\
\hline \multicolumn{3}{|l|}{ Subject profile (number of teachers) } \\
\hline - languages (990) & $44.8 \pm 8.5$ & $46.5 \pm 9.2$ \\
\hline - social sciences (220) & $43.7 \pm 9.3$ & $44.6 \pm 9.3$ \\
\hline - natural sciences (1310) & $41.9 \pm 7.7$ & $44.7 \pm 8.3$ \\
\hline - languages and social sciences (1497) & $43.2 \pm 8.3$ & $45.1 \pm 8.9$ \\
\hline - languages and natural sciences (373) & $43.1 \pm 7.8$ & $45.2 \pm 8.4$ \\
\hline - social sciences and natural sciences (471) & $42.5 \pm 7.4$ & $44.7 \pm 8.2$ \\
\hline - art, music, sports (126) & $39.2 \pm 6.7$ & $42.0 \pm 7.6$ \\
\hline - subject combinations with art, music, sports (1122) & $41.6 \pm 7.7$ & $42.2 \pm 8.6$ \\
\hline F-value & 19.96 & 7.13 \\
\hline$p$-value ( $\eta_{\text {partial-value) }}^{2}$ & $<0.001(0.022)$ & $<0.001(0.008)$ \\
\hline
\end{tabular}

Notes: $M \pm S D$ mean \pm standard deviation. Univariate variance analyses; test variable: F-value; $\mathrm{df}=2$; error def $=6,104$; post-hoc test: Bonferroni; $p$-value: significance ( $t$ wo-sided); $\eta_{\text {partial }}^{2}$ partial eta square (effect size): $0.010-0.060=$ small effect, $<0.010=$ none effect [41]

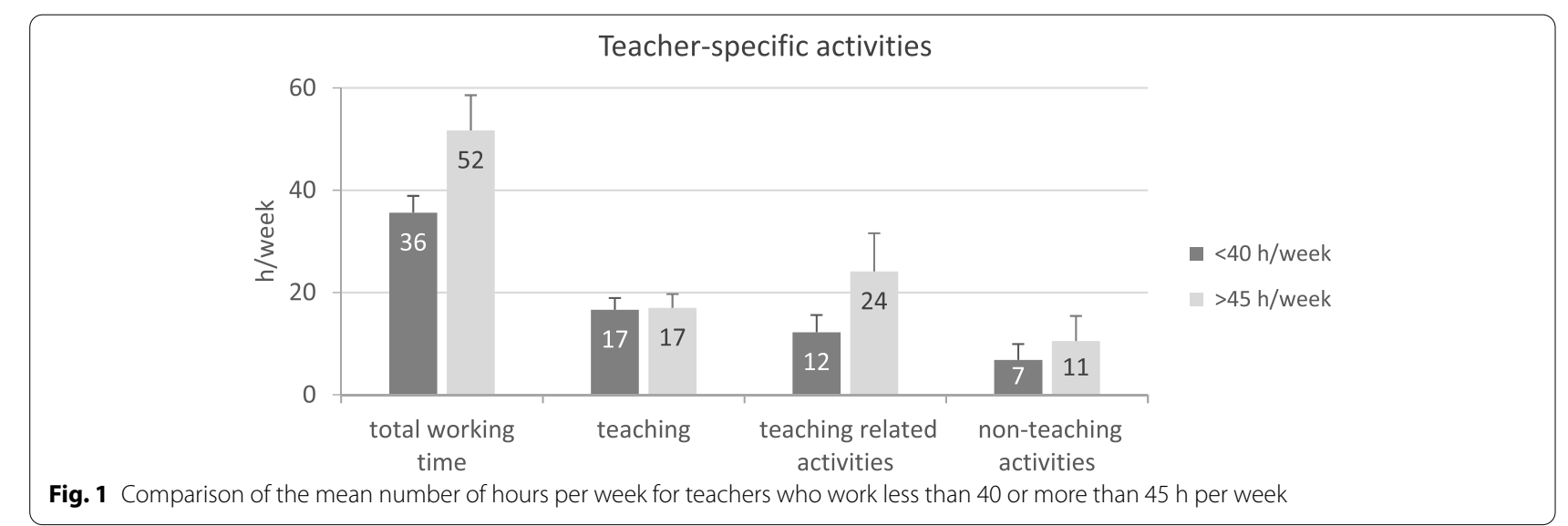

teachers. This means that with a WWT of more than 45 $\mathrm{h}$, only every second teacher succeeds in recovering sufficiently from the workload.

However, the correlation analyses only partially support these statements, because only $8 \%$ of the health characteristics tested here can be explained by the different amount of working time. The clearest correlation is between weekly working hours and the ability to recover $(\mathrm{r}=0.29)$, with a trend of increased weekly working hours being associated with increased inability to recover. 
Table 5 Comparison of inability to recover and emotional exhaustion depending on weekly working hours

\begin{tabular}{|c|c|c|c|c|c|c|c|c|}
\hline \multirow[t]{3}{*}{ Variables } & \multicolumn{6}{|c|}{ Weekly working hours of teachers [h] } & \multicolumn{2}{|c|}{ Significance } \\
\hline & \multicolumn{2}{|c|}{ Total $(n=4779)$} & \multicolumn{2}{|c|}{$<40(n=1796)$} & \multicolumn{2}{|c|}{$>45(n=2983)$} & \multirow[t]{2}{*}{$x^{2}$-value } & \multirow[t]{2}{*}{$p$-value (effect size d) } \\
\hline & $\mathbf{n}$ & $\%$ & $\mathbf{n}$ & $\%$ & $\mathrm{n}$ & $\%$ & & \\
\hline \multicolumn{9}{|l|}{ Inability to recover $(\mathrm{IR})[6-24 \mathrm{pts}]$} \\
\hline - normal (6 - 18 pts) & 2935 & 61.4 & 1328 & 73.9 & 1607 & 53.9 & 196.28 & $<0.001(0.414)$ \\
\hline - noticeable (19-20 pts) & 895 & 18.7 & 252 & 14.0 & 643 & 21.6 & & \\
\hline - very noticeable ( $\geq 21$ - 24 pts) & 949 & 19.9 & 216 & 12.0 & 733 & 24.5 & & \\
\hline \multicolumn{9}{|c|}{ Emotional exhaustion (EE) [0 - $6 \mathrm{pts}]$} \\
\hline - Iow ( $\leq 2.0 \mathrm{pts})$ & 2226 & 46.6 & 982 & 54.7 & 1244 & 41.7 & 83.99 & $<0.001(0.268)$ \\
\hline - normal (>2.0 - <3.2 pts) & 1186 & 24.8 & 413 & 23.0 & 773 & 25.9 & & \\
\hline - high ( $\geq 3.2-6.0$ pts) & 1367 & 28.6 & 401 & 22.3 & 966 & 32.4 & & \\
\hline
\end{tabular}

Notes: $n$ number of teachers, pts points; \%: frequency in \%. Chi-square test (Pearson); test size: $\chi^{2}$-value; $p$-value: significance (two-sided); effect size d: 0.2 - $0.4=$ small effect [41]

For emotional exhaustion, this correlation is very low ( $\mathrm{r}$ $=0.18$ ). Ability to recover and emotional exhaustion correlate moderately $(\mathrm{r}=0.59)$ with a variance explanation of $35 \%$.

\section{Discussion}

\section{Long working hours and effects on mental health}

The results of the study show that several teachers at German upper-level secondary schools work long hours per week even in phases of average workload. More than a third of the teachers examined exceed the statutory maximum work limit of $48 \mathrm{~h}$ per week. Over 15\% of teachers document weekly working hours above $55 \mathrm{~h}$, a limit that is associated with an increase in the risk of cardiovascular diseases and depression [15, 44].

The long weekly working hours are mainly the result of the individual workload for tasks that have to be done in addition to the 17 compulsory teaching hours. These tasks are often conducted by teachers at home in the evenings and at weekends. This can make it difficult to mentally detach from work. However, this detachment is an important precondition for successful recovery, which is considered a health resource $[19,45,46]$.

Compared to other occupational groups, teachers seem to have less success in mentally detaching themselves from work. Based on a representative survey of German employees, Varol et al. [47] showed that teachers reported difficulties in mentally detaching from work twice as often as other professions ( $42 \%$ vs. $21 \%$ ). The main reasons for this were emotional demands as well as time and performance pressures. Overall, teachers were the second most frequently affected $(23 \%)$ by recovery problems after managers [48].

The overall weak correlations between working hours and recovery ability or emotional exhaustion in this study suggest that teachers manage their job demands differently and that working hours are less significant than expected. Whether a high number of working hours ultimately becomes a health risk probably depends more on the individual's way of coping these demands. Inability to recover is seen as an individual coping pattern in dealing with job demands and is associated with high work commitment and the acceptance of limited recovery [49]. Teachers with this coping pattern are likely to be more at risk of overestimating their own reserves and suffering from exhaustion.

The data show that teachers who work more than 45 $\mathrm{h}$ per week are significantly more frequently affected by signs of inability to recover and emotional exhaustion compared to those who work less than $40 \mathrm{~h}$ per week. The results presented offer additional evidence that long working hours inhibit recovery processes and increase the risk of emotional exhaustion $[17,50,51]$.

\section{Influence of the recording method}

The results suggest that the method used to record working time is important. The teachers estimated their average weekly working time as significantly shorter $(42.8 \mathrm{~h})$ than they documented in a subsequent four-week period by daily $\log (45.2 \mathrm{~h})$.

It seems to be difficult to estimate the WWT of an average school week. This is not surprising when analysing the documented working hours. No school week resembles any other one. Even the number of lessons varies considerably from week to week, despite the fixed number of compulsory lessons. In addition to the absence of colleagues due to illness, excursions as well as further trainings and extra-curricular activities, all lead to unscheduled changes in the weekly distribution of hours. Such changes cannot be taken into account when 
estimating an average WWT. In this respect, a differentiated daily documentation of individual work activities appears to be more reliable in correctly recording WWT. This view is also held by other authors $[8,52,53]$.

Juster and Stafford [54] postulate that the working hours of an average week can only be validly estimated if daily work patterns have regular schedules, which is rarely the case for teachers. But it is also apparently difficult for other occupational groups to estimate the hours of an average working week. Compared to diary documentation, almost all employees from the most varied of occupational groups overestimated their working hours by $3 \mathrm{~h}$ or more per week $[55,56]$. Contrarily, the fact that teachers tend to underestimate their working hours may be due to their significantly higher weekly working hours during school periods than most of the general population.

Current studies from Germany [34] and Switzerland [29] used selected samples with considerable effort to implement the day-to-day documentation of working hours over an entire educational year (total survey). This form of working time documentation is the gold standard for determining teachers' working hours [54] and is necessary to map fluctuations in the workload within a year as well as to record weekend and holiday working time. However, the personnel and financial effort required for such a total survey is immense.

Despite the diversity of the recording methods used over six decades, Hardwig and Mußmann [6] found surprisingly high agreement of the central findings on working time after a meta-analysis of 20 working time studies for Germany. They concluded “... that well-founded estimation procedures ... can certainly lead to sufficiently precise results if full surveys provide orientation at greater intervals" [ibid. p. 94].

\section{Influence of sex, age and subject profile on working time}

Although the study dealt with a clearly defined sample of full-time, upper-level secondary school teachers, a large variance in the documented WWT (SD $=8-9 \mathrm{~h} /$ week) was observed regardless of the method used. This finding once again confirms the phenomenon known for some time that individual working hours in the teaching profession are very variable and depend on many factors. As observed, dispersion in the WWT can reach a considerably higher level, even within a school type. For example, Jerrim and Sims [35] reported differences in working hours of up to $37 \mathrm{~h}$ per week for English full-time, lowerlevel secondary school teachers. For German upper-level secondary school teachers, Mummert [57] demonstrated that - over a whole year - there are clearly more than $600 \mathrm{~h}$ of work between those who work a lot or very little [ibid., p. 40].
In the study presented here, sex, age, and subject profile emerged as relevant influencing factors for the working hours of teachers. Female teachers work significantly longer than male teachers. In the OP female teachers documented an average of $1.5 \mathrm{~h}$ more working time per week than their male colleagues. This is a remarkable result since previous studies in Germany have reached contradictory conclusions as to whether sex is an influencing factor and, if so, in which direction [6]. The main reason for this contradiction is seen as an overlap of the sex effect with influencing factors such as part-time work, school type and additional functions. To control such confounders, analyses only included data from fulltime teachers at upper secondary schools with up to a three-lesson reduction for additional functions. Also, the teaching obligation for male and female teachers was comparatively high in this study.

The age effect also occurs regardless of the method of recording. It is most evident in the difference of $5 \mathrm{~h}$ per week on average between younger teachers and those just starting $(20-29$ years, WWT $=47 \mathrm{~h})$ and the oldest colleagues ( $60-67$ years, WWT $=42 \mathrm{~h}$ ). It should be noted that $60 \%$ of teachers in the highest age group are allocated one to three fewer lessons per week (age-related reduction) and thus partly save time in the preparation and follow-up of lessons. The number of lessons per week therefore for those aged 60 and over differs by at least $2 \mathrm{~h}$ on average from all other age groups examined. It can be assumed that young professionals need more time than their more experienced colleagues in preparing lessons, and this time is reflected in the WWT. The observation is in turn supported by findings from the TALIS study: early-career teachers with fewer than five years of professional experience work $2.6 \mathrm{~h}$ per week more than those with 6 to 10 years of professional experience and $4.7 \mathrm{~h}$ per week more that those who have been teaching for more than 10 years [26]. This finding is viewed critically because the risk of a career exit is particularly high in the first five years [58].

It is noteworthy that teachers in the age range of 30 and 59 years, on the other hand, almost uniformly document their average WWT in the OP at around $45 \mathrm{~h}$, although different proportions of them (54-64\%) receive a reduced allocation of hours. For English teachers in secondary schools, Micklewright et al. [59] also come to the conclusion that WWT does not differ in the middle age groups and is between 45 and $47 \mathrm{~h}$ on average. Knight Wegenstein [9], however, indicates that a shortening of lesson preparation due to experience was not observed especially among teachers at upper-level secondary schools. Gehrmann [31] describes a working time plateau at around 40 years of age and a drop in WWT after the age of 60 for all school types but considers the influence 
of age to be low overall [ibid. p. 305]. However, he puts forward that thesis that teachers, regardless of age, limit their WWT to about $44 \mathrm{~h}$ in a self-regulatory process, at the expense of teaching quality [ibid., p. $312 \mathrm{ff}$ ] and that if the obligation to teach increases, time for lesson-related activities is reduced.

In relation to the influence of the subject profile, the here presented study shows the highest WWT for teachers who only teach a language profile, followed by those with a social or scientific profile. By contrast, teachers who teach an artistic profile or sport document significantly shorter working hours. The influence of the subject on the total working time is mainly attributed to the subject-dependent effort for the preparation of lessons and the amount of correction $[25,56]$. However, the combination of first and second subject is decisive for the total working time. The results of the study fit into a largely consistent knowledge base of German and international studies on teaching hours based on subjects taught $[6,25]$.

\section{Strength and limitations}

To the best of our knowledge, this study is the first to present data on the working hours of full-time, upper-level secondary school teachers for the whole of Germany, taking into account significant influencing factors and potential health risks. The sample is characterised by a homogeneous collective compared to other teacher studies. A mix of teachers with functionaries (e.g. staff councils) and principals has been consistently avoided. The results confirm on the one hand the known influence of teaching subjects on WWT and on the other hand add new knowledge on the influence of sex and age on working hours. In addition, it makes clear that total working time is influenced by the recording method.

The results presented here should be interpreted in the light of the limitations of this study. Since participation in the study was voluntary, selection effects may have had an impact. For example, the proportion of male school teachers in the study was $8 \%$ lower than the proportion of all male, full-time, upper-level secondary school teachers in Germany. The documentation of working times represented an additional time burden for the teachers, which could have acted as an obstacle in the recruitment of participants. Therefore, it is possible that teachers with heavy professional workloads and private burdens did not take part in the study due to lack of time.

From a methodological perspective, it should be noted that the working time of the teachers was only recorded over a period of 4 weeks and thus only presents an excerpt from the school year. Third subjects taught were not taken into account when creating the subject profiles.
It was assumed that this was only a minor subject with a low teaching obligation.

Personality traits related to work behaviour, such as self-efficacy, conscientiousness and unhealthy perfectionism, were not studied in this paper. This leaves open the question of the extent to which they can have an influence on working hours. Finally, the data collection was conducted as a cross-sectional study, which prevents the findings of causal relationships between independent variables.

\section{Conclusions}

The present results underline the need to consider essential factors influencing the working hours of teachers, both in research and in educational policy decisions. There can be considerable differences in the weekly working hours of teachers depending on professional experience and subject profile. However, excessively long working hours may harbour health risks and lead to a loss of quality in teaching. There is also a risk of early career abandonment for young professionals.

Therefore, working conditions should be arranged in such a way that the volume of work tasks can be managed by any teacher in a reasonable amount of time. A fair distribution of work tasks and opportunities to recover from work regularly and sufficiently are essential health resources for teachers. In addition, teachers should acquire competencies in professional self-regulation from the very beginning of their education. This is an important precondition for successfully coping with the subsequent requirements of the profession. Due to its high demands on flexibility and autonomy, the teaching profession involves the risk of being overburdened. From a preventive medicine perspective, the recording of working time can be a form of individual control that supports teachers in not extending their working hours to an extreme number in order to be able to recover sufficiently.

\section{Abbrevations}

OQ: Online Questionnaire; OP: Online Protocol; IR: Inability to Recover; EE: Emotional Exhaustion; MBI-GS: Maslach Burnout Inventory - General Survey.

\section{Supplementary Information}

The online version contains supplementary material available at https://doi. org/10.1186/s12889-022-12680-5.

Additional file 1. Online Questionnaire (acquisition of socio-demographic and job-related data).

Additional file 2. Online Protocol (recording of daily working time).

Acknowledgements

The scientists are dedicated to all the teachers participated in the research project. 


\section{Authors' contributions}

Study conception and methodology: RS, SK; Funding acquisition: RS; Project administration: RS, SK; Investigation: RS, SK, CF; Formal analysis: RS; Analysis and interpretation of data: RS, SK, CF; Writing - original draft preparation: SK, RS; Final approval and critical review of the version to be published: SK, RS, CF. The authors declare that the manuscript has neither been published nor submitted for publication. All authors have released the manuscript for submission.

\section{Funding}

Open Access funding enabled and organized by Projekt DEAL. Partial financial support was received from the German Association of Philologists (DPhV). The sponsor was not involved in data collection, analysis, interpretation, manuscript preparation or the decision to publish.

\section{Availability of data and materials}

The dataset supporting the conclusions of this article is not included within the article on the basis of agreed data protection commitments to the participants.

\section{Declarations}

\section{Consent of publication}

Not applicable

\section{Ethics approval and consent to participate}

All procedures performed were in accordance with the Helsinki declaration or comparable ethical standards. The design and all details of the study were approved by the Ethics Committee at the Rostock University Medical Center (A 2018-0031). Participants were informed about the study purpose, methods, and confidentiality of data. Written informed consent was given by every participant prior to the inclusion in the study. The analyses were carried out in accordance with the relevant guidelines and regulations.

\section{Competing interests}

The authors declare that they have no competing interests.

Received: 1 February 2021 Accepted: 31 January 2022

Published online: 14 February 2022

\section{References}

1. Bakker AB, Hakanen JJ, Demerouti E, Xanthopoulou D. Job resources boost work engagement, particularly when job demands are high. J Educ Psychol. 2007:99:274-84. https://doi.org/10.1037/0022-0663.99.2.274.

2. Collie RJ, Shapka JD, Perry NE. School climate and social-emotional learning: predicting teacher stress, job satisfaction, and teaching efficacy. J Educ Psychol. 2012;104:1189-204. https://doi.org/10.1037/a0029356.

3. Klassen RM, Chiu MM. Effects on teachers' self-efficacy and job satisfaction: teacher gender, years of experience, and job stress. J Educ Psychol. 2010;102:741-56. https://doi.org/10.1037/a0019237.

4. Skaalvik EM, Skaalvik S. Job satisfaction, stress and coping stategies in the teaching profession - what do teachers say? Int Educ Stud. 2015;8:181-92. https://doi.org/10.5539/ies.v8n3p181.

5. Skaalvik EM, Skaalvik S. Job demands and job resources as predictors of teacher motivation and well-being. Soc Psychol Educ. 2018;21:1251-75. https://doi.org/10.1007/s11218-018-9464-8.

6. Hardwig T, Mußmann F. Zeiterfassungsstudien zur Arbeitszeit von Lehrkräften in Deutschland-Konzepte, Methoden und Ergebnisse von Studien zu Arbeitszeiten und Arbeitsverteilung im historischen Vergleich: GOEDOC, Dokumenten- und Publikationsserver der Georg-AugustUniversität Göttingen. 2018. http://resolver.sub.uni-goettingen.de/purl/? webdoc-3982. Accessed 08 Dec 2021.

7. Organisation for Economic Cooperation and Development (OECD). TALIS 2018 Results (Volume I); 2019. https://doi.org/10.1787/1d0bc92a-en. Accessed 08 Dec 2021

8. West K. New measures of teachers' work hours and implications for wage comparisons. Educ Finance Policy. 2014;9:231-63. https://doi.org/10. 1162/EDFP-a-00133.
9. Knight Wegenstein AG. Die Arbeitszeit der Lehrer in der Bundesrepublik Deutschland. Band I: Analyse, Band II: Katalog für Zeitaufwand. Zürich; 1973.

10. Angrave D, Charlwood A. What is the relationship between long working hours, over-employment, under-employment and the subjective well-being of workers? Longitudinal evidence from the UK. Hum Relat. 2015:68:1491-515. https://doi.org/10.1177/0018726714559752.

11. Wunder C, Heineck G. Working time preferences, hours mismatch and well-being of couples: are there spillovers? Labour Econ. 2013;24:244-52. https://doi.org/10.1016/j.labeco.2013.09.002.

12. Afonso $P$, Fonseca M, Pires JF. Impact of working hours on sleep and mental health. Occup Med. 2017;67:377-82. https://doi.org/10.1093/occmed/ kqx054.

13. Bannai A, Tamakoshi A. The association between long working hours and health: a systematic review of epidemiological evidence. Scand J Work Environ Health. 2015;40:5-18. https://doi.org/10.5271/sjweh.3388.

14. Van der Hulst M. Long work hours and health. Scand J Work Environ Health. 2003;29:171-88. https://doi.org/10.5271/sjweh.720.

15. Virtanen $M$, Kivimäki M. Long working hours and risk of cardiovascular disease. Curr Cardiol Rep. 2018;20:123. https://doi.org/10.1007/ s11886-018-1049-9.

16. Wong K, Chan AHS, Ngan SC. The effect of long working hours and overtime on occupational health: a meta-analysis of evidence from 1998 to 2018. Int J Environ Res Public Health. 2019;16:2102. https://doi.org/10. 3390/ijerph16122102.

17. Hu NC, Chen JD, Cheng TJ. The associations between long working hours, physical inactivity, and burnout. J Occup Environ Med. 2016:58:514-8. https://doi.org/10.1097/JOM.0000000000000715.

18. Felsing C, Seibt R, Stoll R, Kreuzfeld S. Working time structure of secondary school teachers in the course of the day and the week - an app-based pilot study. Arbeitsmed Sozialmed Umweltmed. 2019:54:47-55.

19. Sonnentag S, Fritz C. Recovery from job stress: the stressor-detachment model as an integrative framework. J Organ Behav. 2015;36(Suppl 1):72-103. https://doi.org/10.1002/job.1924.

20. Sonnentag S. Recovery, work engagement, and proactive behavior: a new look at the interface between nonwork and work. J Appl Psychol. 2003;88:518-28. https://doi.org/10.1037/0021-9010.88.3.518.

21. Wepfer AG, Allen TD, Brauchli R, Jenny GJ, Bauer GF. Work-life boundaries and well-being: does work-to-life integration impair well-being through lack of recovery? J Bus Psychol. 2018;33:727-40. https://doi.org/10.1007/ s10869-017-9520-y.

22. Meijman TF, Mulder G. Psychological aspects of workload. In: Drenth PJD, Thierry H, De Wolff CJ, editors. Handbook of work and organizational psychology. Hove: Psychology Press/Erlbaum; 1998. p. 5-33.

23. Hübner $P$, Werle M. Arbeitszeit und Belastung Berliner Lehrerinnen und Lehrer. In: Buchen S, Carle U, Döbrich P, Hoyer HD, Schönwälder HG, editors. Jahrbuch für Lehrerforschung. Weinheim: Juventa; 1997. p. 203-26.

24. Seibt R, Matz A, Hegewald J, Spitzer S. Working conditions of female parttime and full-time teachers in relation to health status. Int Arch Occup Environ Health. 2012;85:675-87. https://doi.org/10.1002/job.1924.

25. Sellen P. Teacher workload and professional development in England's secondary schools: insights from TALIS. London: Education Policy Institute; 2016. https://epi.org.uk/publications-and-research/teacher-workl oad-professional-development-englands-secondary-schools-insightstalis/. Accessed 08 Dec 2021

26. Walker M, Worth J, Van den Brande J. Teacher workload survey 2019. UK: National Foundation for Educational Research, 2019. https://assets.publi shing.service.gov.uk/government/uploads/system/uploads/attachment_ data/file/855933/teacher_workload_survey_2019_main_report_amend ed.pdf. Accessed 08 Dec 2021

27. European Commission/Eurydice. Key data on teachers and school leaders in Europe. Luxembourg: Publications Office of the European Union; 2013. https://doi.org/10.2797/91785.

28. Organisation for Economic Cooperation and Development (OECD). Education at a Glance 2019. https://www.oecd-ilibrary.org/content/publi cation/f8d7880d-en. Accessed 08 Dec 2021.

29. Brägger M. LCH Arbeitszeiterhebung 2019. Bericht zur Erhebung bei 10.000 Lehrpersonen. Dübendorf, Schweiz.

30. Philipp A, Kunter M. How do teachers spend their time? A study on teachers'strategies of selection, optimisation, and compensation over their 
career cycle. Teach Teach Educ. 2013;35:1-12. https://doi.org/10.1016/j. tate.2013.04.014.

31. Gehrmann A. Der professionelle Lehrer: Muster der Begründung -empirische Rekonstruktion. Opladen: Leske Budrich; 2003.

32. Felsing C, Kreuzfeld S, Stoll R, Seibt R. App-basierte vs. geschätzte Ermittlung der Arbeitszeit von Gymnasiallehrkräften. Präv Gesundheitsf. 2019;14:281-9. https://doi.org/10.1007/s11553-018-0682-x.

33. Mummert P. Untersuchung zur Ermittlung, Bewertung und Bemessung der Arbeitszeit der Lehrerinnen und Lehrer im Land Nordrhein-Westfalen. Hamburg: Ministerium für Schule und Weiterbildung, Wissenschaft und Forschung des Landes Nordrhein-Westfalen; 1999.

34. Mußmann F, Hardwig T, Riethmüller M. Niedersächsische Arbeitsbelastungsstudie 2016 - Lehrkräfte an öffentlichen Schulen. Ergebnisbericht. 2017. https://doi.org/10.3249/webdoc-3974.

35. Jerrim J, Sims S. The Teaching and Learning International Survey (TALIS) 2018. University College of London, Institute of Education. 2019. https:// dera.ioe.ac.uk//33612/. Accessed 08 Dec 2021.

36. Seibt R, Spitzer S, Druschke D, Scheuch K, Hinz A. Predictors of mental health in female teachers. Int J Occup Med Environ Health. 2013;26:85669. https://doi.org/10.2478/s13382-013-0161-8.

37. Richter P, Rudolf M, Schmidt CF. FABA: Fragebogen zur Erfassung beanspruchungsrelevanter Anforderungsbewältigung. Frankfurt/M: Harcourt Test Service; 1996.

38. Richter P, Rotheiler E, Rudolf M. FABA - Fragebogen zur Analyse belastungsrelevanter Anforderungsbewältigung. 2nd ed. Mattersburg: P \& T Prieler Tometich: Potentialanalyse und Testverfahren GmbH; 2015.

39. Blanz M. Forschungsmethoden und Statistik für die Soziale Arbeit: Grundlagen und Anwendungen. Stuttgart: Kohlhammer; 2015.

40. Schaufeli WB, Leiter MP, Maslach C, Jackson SE. In: Maslach C, Jackson SE, Leiter MP, editors. Maslach Burnout Inventory - General Survey. 3rd ed. Palo Alto: Consulting Psychologists Press; 1996. p. 19-26.

41. Cohen J. Statistical power analysis for the behavioral sciences. 2nd ed. Hillsdale: Lawrence Erlbaum Associates; 1988. p. 40.

42. Seibt R, Kreuzfeld S. Influence of work-related and personal characteristics on the burnout risk among full- and part-time teachers. Int J Environ Res Public Health. 2021;18:1535.

43. Bühl ASPSS. 23. Einführung in die moderne Datenanalyse. Hallbergmoos: Pearson; 2016.

44. Kivimäki M, Jokela M, Nyberg ST, Ferrie JE, Virtanen M. Long working hours and risk of coronary heart disease and stroke: a systematic review and meta-analysis of published and unpublished data for 603838 individuals. Lancet. 2015;386:1739-46. https://doi.org/10.1016/S01406736(15)60295-1.

45. Virtanen A, De Bloom J, Kinnunen U. Relationships between recovery experiences and well-being among younger and older teachers. Int Arch Occup Environ Health. 2020;93:213-27. https://doi.org/10.1007/ s00420-019-01475-8.

46. Cropley M, Rydstedt LW, Devereux JJ, Middleton B. The relationship between work-related rumination and evening and morning salivary cortisol secretion. Stress Health. 2015;31:150-7. https://doi.org/10.1002/ smi.2538.

47. Varol YZ, Weiher GM, Wendsche J, Lohmann-Haislah A. Difficulties detaching psychologically from work among German teachers: prevalence, risk factors and health outcomes within a cross-sectional and national representative employee survey. BMC Public Health. 2021;21:2046. https://doi. org/10.1186/s12889-021-12118-4.

48. Schulz AD, Wendsche J, Lohmann-Haislah A, Schöllgen I. Erholungsbeeinträchtigungen bei Beschäftigten. Zbl Arbmed. 2020;70:57-65. https://doi. org/10.1007/s40664-019-00373-7.

49. Richter P, Rudolf M, Schmidt CF. Fragebogen zur Analyse belastungsrelevanter Anforderungsbewältigung: FABA. Frankfurt am Main: Swets \& Zeitlinger; 1999.

50. Kijima S, Tomihara K, Tagawa M. Effect of stress coping ability and working hours on burnout among residents. BMC Med Educ. 2020;20:219. https://doi.org/10.1186/s12909-020-02134-0.

51. Bannai A, Ukawa S, Tamakoshi A. Long working hours and psychological distress among school teachers in Japan. J Occup Health. 2015;57:20-7. https://doi.org/10.1539/joh.14-0127-OA.

52. Bonke J. Paid work and unpaid work: diary information versus questionnaire information. Soc Indic Res. 2005;70:349-68. https://doi.org/10.1007/ s11205-004-1547-6.
53. Naylor C. Teacher workload and stress: an international perspective on human costs and systemic failure. BCTF-Research Report, British Columbia Teachers'Federation, Vancouver. 2001. https://eric.ed.gov/?id=ED464 028. Accessed 08 Dec 2021

54. Juster FT, Stafford FP. The allocation of time: empirical findings, behavioral models, and problems of measurement. J Econ Lit. 1991;29:471-522.

55. Frazis $\mathrm{H}$, Stewart J. What can time-use data tell us about hours of work? Mon Labor Rev. 2004;127:3-9.

56. Robinson J, Chenu A, Alvarez A. Measuring the complexity of hours at work: the weekly work grid. Mon Labor Rev. 2020;125:44-54.

57. Mummert Consulting AG. Das Lehrerarbeitszeitmodell in Hamburg. Bericht zur Evaluation. 2005. https://www.hamburg.de/contentblob/70404/ 4d6ae063cc3257119445643de75349a1/data/laz-bericht-kurzfassung.pdf. Accessed 08 Dec 2021

58. Foster D. Teacher recruitment and retention in England. House of Commons briefing paper 7222. House of Commons library, UK. 2018. https:// commonslibrary.parliament.uk/research-briefings/cbp-7222/. Accessed 08 Dec 2021.

59. Micklewright J, Jerrim J, Vignoles A, Jenkins A, Allen R, llie S, et al. Teachers in England's secondary schools: evidence from TALIS 2013. University of London, Institute of Education. 2014. https://dera.ioe.ac.uk//20391/. Accessed 08 Dec 2021.

\section{Publisher's Note}

Springer Nature remains neutral with regard to jurisdictional claims in published maps and institutional affiliations.

Ready to submit your research? Choose BMC and benefit from:

- fast, convenient online submission

- thorough peer review by experienced researchers in your field

- rapid publication on acceptance

- support for research data, including large and complex data types

- gold Open Access which fosters wider collaboration and increased citations

- maximum visibility for your research: over 100M website views per year

At BMC, research is always in progress.

Learn more biomedcentral.com/submissions 